\title{
Corrigendum para: As diferentes narrativas alimentares do agronegócio
}

\section{Caio POMPEIA ${ }^{1 *}$, Sergio SCHNEIDER ${ }^{2}$}

${ }^{1}$ Universidade de São Paulo (USP), São Paulo, SP, Brasil.

${ }^{2}$ Universidade Federal do Rio Grande do Sul (UFRGS), Porto Alegre, RS, Brasil.

*E-mail de contato: caporine@gmail.com

Artigo recebido em 8 de outubro de 2020, versão final aceita em 6 de abril de 2021, publicado em 30 de junho de 2021.

O artigo original pode ser encontrado online em:

http://dx.doi.org/10.5380/dma.v57i0.77248

Na página 178, onde se lê:

"Estudos da área de saúde pública, medicina, nutrição e epidemiologia estão apontando relações causais entre a alimentação inadequada e tais doenças (Popkin \& Reardon, 2018; Tilman \& Clark, 2014; Willet et al. 2019).”

\section{Leia-se:}

"Estudos da área de saúde pública, medicina, nutrição e epidemiologia estão apontando associações entre a alimentação inadequada e tais doenças (Popkin \& Reardon, 2018; Tilman \& Clark, 2014; Willet et al. 2019)."

Na página 191, onde se lê:

“Ao robustecer a identificação de relações causais entre, de um lado, o crescimento do consumo de alimentos e bebidas ultraprocessados, e, de outro, o aumento na ingestão calórica e no ganho de gordura corporal no país (ver, por exemplo, Louzada et al., 2015), a NOVA foi determinante para a ampliação do conhecimento científico de fatores contribuintes à deterioração característica da transição nutricional brasileira, como atestam os preocupantes números apresentados no início deste artigo.” 
Leia-se:

“Ao robustecer a identificação de associações entre, de um lado, o crescimento do consumo de alimentos e bebidas ultraprocessados, e, de outro, o aumento na ingestão calórica e no ganho de gordura corporal no país (ver, por exemplo, Louzada et al., 2015), a NOVA foi determinante para a ampliação do conhecimento científico de fatores contribuintes à deterioração característica da transição nutricional brasileira, como atestam os preocupantes números apresentados no início deste artigo."

Publicado em: 12 de julho de 2021.

DOI: $10.5380 / \mathrm{dma} . v 57 \mathrm{i} 0.81899$ 